\title{
An Electro-Hydraulic Servo with Intelligent Control Strategy
}

\author{
Saeed Mohammed ${ }^{1}$, Chong Chee Soon ${ }^{1}$, Rozaimi Ghazali ${ }^{1, *}$, Ahmad Anas Yusof ${ }^{2}$, Yahaya Md Sam ${ }^{3}$, and Chai Mau \\ Shern ${ }^{1}$ \\ ${ }^{1}$ Centre for Robotics and Industrial Automation, Faculty of Electrical Engineering, Universiti Teknikal Malaysia Melaka, Hang \\ Tuah Jaya, 76100 Durian Tunggal, Melaka, Malaysia. \\ ${ }^{2}$ Faculty of Mechanical Engineering, Universiti Teknikal Malaysia Melaka, Hang Tuah Jaya, 76100 Durian Tunggal, Melaka, \\ Malaysia. \\ ${ }^{3}$ Department of Control and Mechatronic Engineering, Faculty of Electrical Engineering, Universiti Teknologi Malaysia, 81310 \\ Skudai, Johor, Malaysia
}

\begin{abstract}
Versatile engineering applications have been developed to assist, reduce, and avoid human being from any heavy or harmful manufacturing processes. The gradually increased demand in force and position controls have simultaneously increased the usage of Electro-Hydraulic Servo (EHS) system. However, the time varying characteristics such as high-speed, outburst starting and stopping dynamic have led the EHS system to suffer from uncertainties and nonlinearities effects. Therefore, in order to enhance the performance of an EHS to surmount the uncertain and nonlinear effects, a hybrid Fuzzy-PID control strategy is developed which particularly improve the accuracy of the system by enhancing the control performance during the positioning tracking. By measuring the performance of the proposed control approach, the transient response and steady-state analysis will be performed which taking linear and intelligent control strategies as the references in the assessment process. The finding indicates the capability of a hybrid Fuzzy-PID controller in reducing the control effort applied to the EHS system.
\end{abstract}

\section{Introduction}

An actuator system is a device that produces mechanical movement by changing different type of energies into mechanical energy. The sources of the force are whether a supply from electrical motor, pneumatic pressure or hydraulic pressure. Hence, an actuator is classified according to the source of supply. The hydraulic actuator is an actuator system that utilizes pressurized hydraulic fluid, which is functioned as a drive or a transmission system to generating a dynamic [1]. A common structure of an EHS system composed of hydraulic fluid, control valve and cylinder [2].

The hydraulic actuator is widely used in industry due to its ability in generating large torque, capable of generating high power, and produce good positioning with fast motion [3]. Due to its capabilities, the hydraulic system has been used in many applications such as power system [4], braking systems [5], manufacturing system [6], flight simulation [7, 8], and cranes [9-11]. The low input power is converted into a high torque movement that used to control hydraulic applications.

However, the nonlinear electro-hydraulic system is suffering from nonlinearities and time varying characteristics such as high speed, outburst starting and stopping dynamic that produced by the flow and the pressure in the hydraulic system. The nonlinear properties causing a backlash in the control valve, actuator friction, distinction in fluid volume that make the system models and controller designs more complex [12].

The nonlinear properties that are produced through pressure and flow rate of the hydraulic system required a suitable controller to achieve better performances. In the previous works, there are many type of control techniques have been reported, which can be utilized to control the tracking capability of a nonlinear electrohydraulic actuator system. Each of the control techniques required a proper tuning technique and some of the advanced tuning techniques have been reported recently such as Particle Swarm Optimization (PSO) [13-18], Genetic Algorithm (GA) [19-21], and Differential Evolution (DE) [22, 23].

All the controllers may be successfully controlled the nonlinear electro-hydraulic actuator. However, the output performance will be different. The numerical analysis such as system overshoot, settling time and steady-state error will be different for each type of control techniques. This paper proposed a hybrid FuzzyPID control approach to dealing with the nonlinear characteristic of the EHS system. It is observed from the literatures, there are not much comparison studies for this type of controller in term of transient response and steady state error evaluation. Therefore, an attempt to compare these numerical analyses for the proposed control strategies have been implemented in this paper.

\footnotetext{
* Corresponding author: rozaimi.ghazali@utem.edu.my
} 
By using a hybrid Fuzzy-PID controller, the performance of the system can be adjusted to having less overshoot, steady state error, faster settling and rising time.

This paper is organized as, the common introduction regarding the EHS system, the basic mathematical modelling of the EHS system, and the theoretical explanation of the Fuzzy-PID controller are presented in Section 2. Section 3 presents the performance of the proposed control approach implemented in the EHS system. Finally, the conclusion will be drawn in Section 5.

\section{Basic Structure of the EHS System}

The development of the physical model for the EHS system will be done by using MATLAB/Simulink 2016 software. In this study, the EHS system will be first modelled according to the mathematical modelling of the EHS system based on the first principles of the physical law as discussed in [24]. After the formation of the EHS system, the proposed Fuzzy-PID controller will be applied, which is particularly applied to control the displacement of the EHS system. Fig. 1 [25] indicates the basic structure of the EHS system in this study.

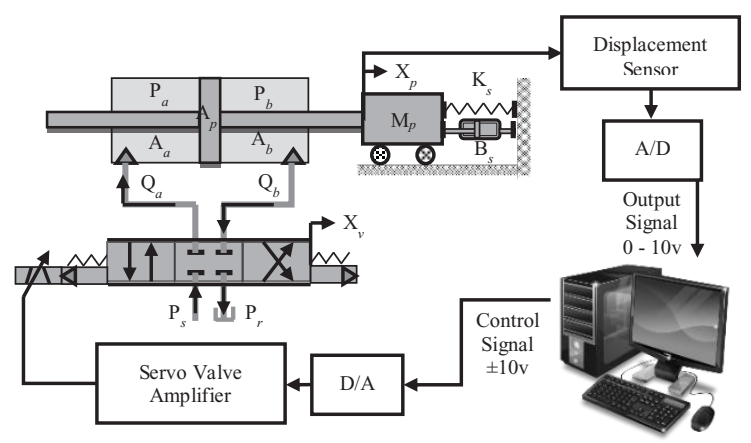

Fig. 1. Basic structure of the EHA system

The error value is identified by the sensor that measure the output value, which will be subtracted with the desired input value. This error value is then flows to the controller followed with some calculation of the controller parameters to obtain new output parameters.

Theoretically, the dynamic of the hydraulic servovalve can be illustrated in general second order equation as:

$$
\frac{d^{2} x_{v}}{d t^{2}}+2 \xi \omega_{n} \frac{d x_{v}}{d t}+\omega_{n}^{2}=\frac{I}{I_{s a t}} \omega_{n}^{2}
$$

where $x_{v}$ is the displacement of the servovalve spool, $w_{n}$ is the natural frequency, $\xi$ is the damping ratio, $I / I_{\text {sat }}$ is the normalized input current, and $I$ is the input current.

The flow rate through the servovalve of the hydraulic system is directly proportional to the spool motion and the square root under constant load or varying load condition. An ideal servovalve has a perfect geometry and written as:

$$
Q=K \cdot x_{v} \cdot \sqrt{\Delta P_{v}}
$$

The cylinder of the hydraulic consists of two chambers A and B. Each chamber has volume and pressure as shown in the equations (3)-(6).

$$
\begin{gathered}
V_{a}=V_{\text {line }}+A_{a}\left(x_{s}+x_{p}\right) \\
P_{a}=\frac{\beta}{V_{\text {line }}+A_{p}\left(x_{s}+x_{p}\right)} \int\left(Q_{a}-q_{a b}-q_{a}-\frac{d V_{a}}{d t}\right) d t \\
V_{b}=V_{\text {line }}+A_{b}\left(x_{s}-x_{p}\right) \\
P_{b}=\frac{\beta}{V_{\text {line }}+A_{p}\left(x_{s}-x_{p}\right)} \int\left(\frac{d V_{b}}{d t}-Q_{b}-q_{b a}-q_{b}\right) d t
\end{gathered}
$$

From the total dynamic equations, the force exerted by the hydraulic cylinder against the load is shown in equation (7).

$$
F_{p}=M_{p} \frac{d^{2} x_{p}}{d t^{2}}+B_{s} \frac{d x_{p}}{d t}+K_{s} x_{p}+F_{f}
$$

\subsection{Integration of the Fuzzy-PID Controller}

The development of the EHS system which consists of controller and sensor are demonstrated in the block diagram in Fig. 2.

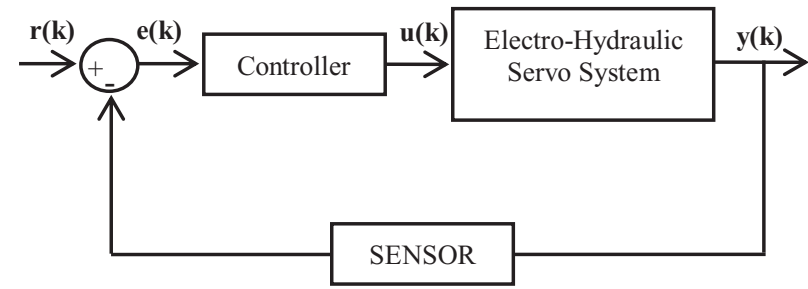

Fig. 2. Basic block diagram of the EHA system

where $r(k)$ denotes the required performance, $u(k)$ is the input signal fed to the hydraulic plant, $y(k)$ is the output performance of the positioning tracking by using the proposed hybrid controller, and $e(k)$ represents the error occurred during the execution process.

By designing the Fuzzy-PID control strategy which is developed based on Fuzzy control theory, the basic concept of the Fuzzy control approach is illustrated is block-diagram in Fig. 3.

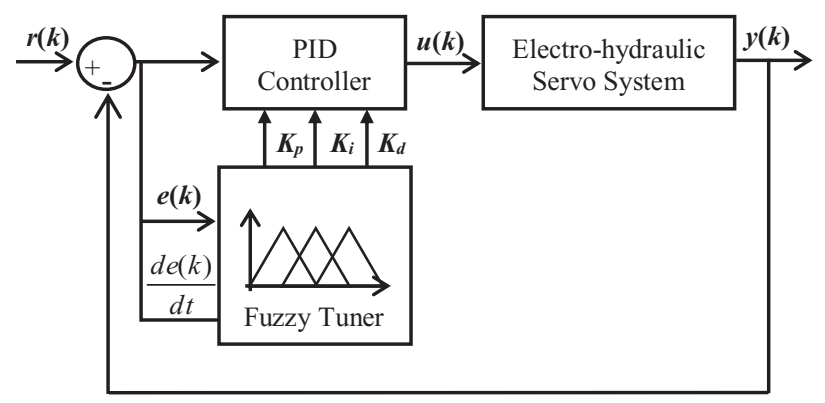

Fig. 3. Integration of the hybrid Fuzzy-PID controller 
Since the assistant of the Fuzzy Logic control approach applied to the PID controller is proven to be performed better [7], therefore, the important properties of the Fuzzy Logic will be used to tuned the PID controller to obtain an optimal result for the EHS system that dealing with large amount of parameter variation [26].

Firstly, the conventional PID parameters obtained through the auto tune and the Ziegler-Nichols tuning techniques will be used as the initial value. Then, the Fuzzy control theory will be applied to tune the PID controller for the purpose of improving the positioning tracking capability of the controller. By adopting the gain value that effect on the transient response and the steady-state error, the inputs and outputs of the Fuzzy Logic will be first defined. The inputs consist of the feedback error $e(t)$ and the derivative of the error $d e(t) / d t$. While the outputs are the PID gains, including $K_{p}, K_{i}$ and $K_{d}$ as shown in Fig. 4.

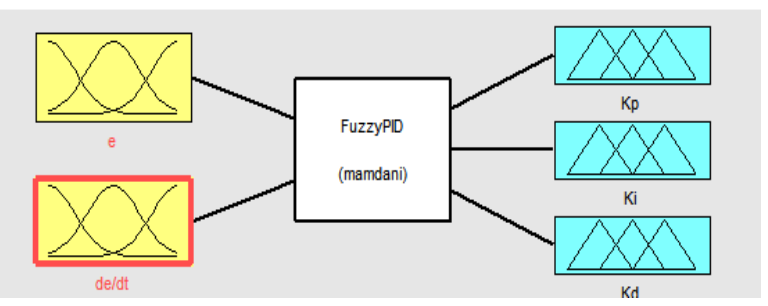

Fig. 4. Inputs and outputs of the Fuzzy-PID controller

The design rules for Fuzzy-PID related to the characteristic of the processes will be set according to the membership functions of the input error, which are composed of three linguistic variables for the change of error, and four rules are applied to design the Fuzzy-PID controller for example, if the error is negative and the change of error is zero, then the outputs must be $K_{p}$ negative, $K_{i}$ positive medium, and $K_{d}$ positive medium as shown in Fig. 5.

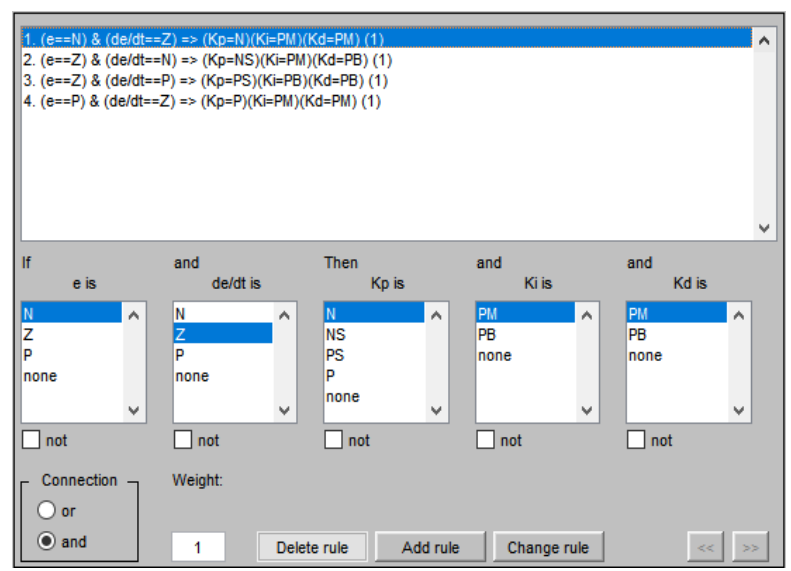

Fig. 5. The design rules for the Fuzzy-PID controller

\section{Results and Discussion}

In order to control the positioning tracking of the nonlinear EHS system, the PID controller has been first applied. Then, the Fuzzy controller has been utilized to improve the performance of the EHS system. Followed by the integration of the Fuzzy-PID controller that will significantly enhance the performance of the EHS system. Fig. 6 depicts the Fuzzy-PID development in the Simulink environment. The parameter values of the PID controller are tuned by using Fuzzy Logic according to the membership function. The scaling factors obtained through the Fuzzy Logic tuning approach including $K_{l}$, $K_{2}$, and $K_{3}$ are 20.5, 0.458 and 1.5 respectively.

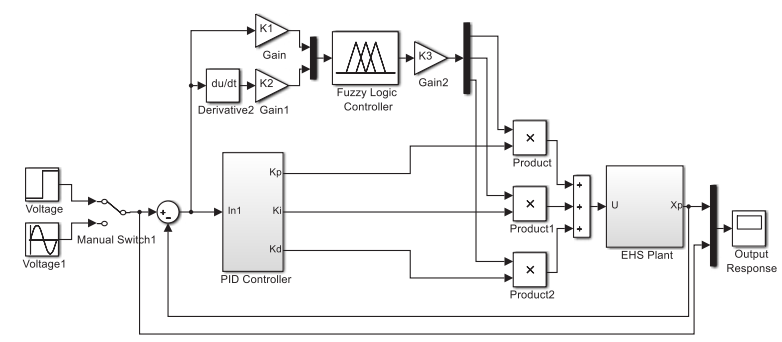

Fig. 6. Development of Fuzzy-PID controller in the Simulink environment.

Fig. 7 demonstrates the Simulink model of the EHS system that composes of the PID controller, Fuzzy logic controller, and Fuzzy-PID controller.

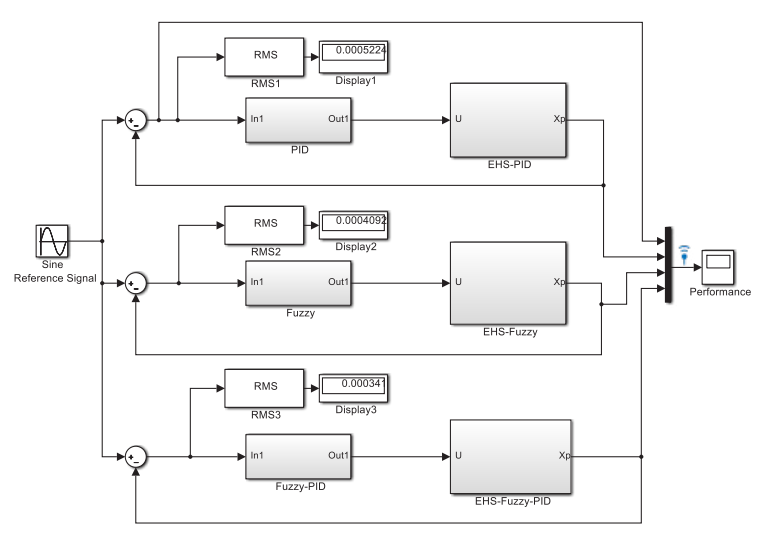

Fig. 7. Three different controllers applied to the EHS system

For the evaluation purposes, the EHS system has been executed with the step and sinusoidal references signal as depicted in Fig. 8 and 9, respectively.

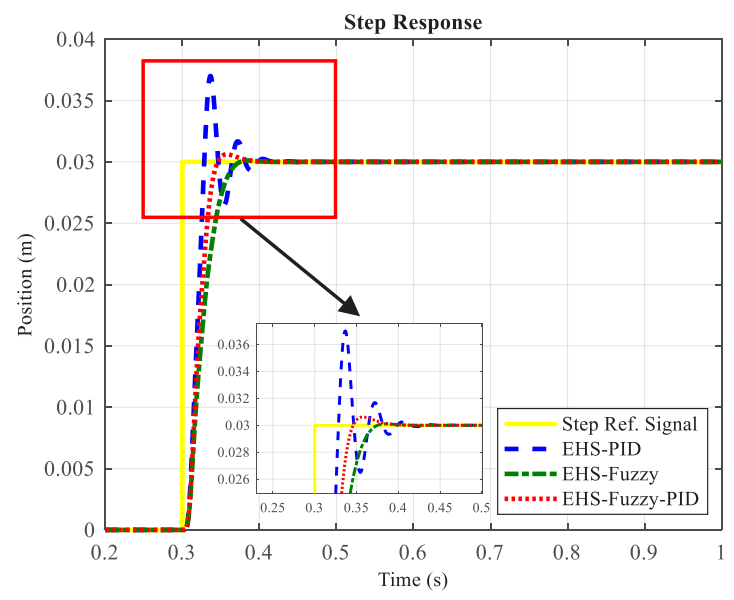

Fig. 8. The response of the controllers to a step reference signal 
For the step reference signal with the results of PID, Fuzzy and Fuzzy-PID, the performance is assessed in term of its steady state error $\left(e_{s s}\right)$ and transient response performance, including overshoot (OS), settling time $\left(T_{s}\right)$, and rise time $\left(T_{r}\right)$. The numerical analysis is tabulated in Table 1. As indicates in Table 1, the overshoot of the PID, Fuzzy, and Fuzzy-PID controllers are $23.33 \%, 0.33 \%$, and $2 \%$ respectively. The results indicate the Fuzzy Logic controller is able to eliminate the overshoot better than the others two controllers. However, for the settling time and rise time, the FuzzyPID controller is outperformed PID and Fuzzy logic controller. The fast response is essential for the EHS system in real-time applications since EHS system is dealing with the time delay in nature. Although the overshoot of the Fuzzy-PID is higher, the limit is in acceptable boundary.

Table 1. The transient response and steady state error analysis

\begin{tabular}{|c|c|c|c|c|}
\hline Controller & OS\% & $\boldsymbol{T}_{\boldsymbol{s}}(\mathbf{s})$ & $\boldsymbol{T}_{\boldsymbol{r}}(\mathbf{s})$ & $\boldsymbol{e}_{\boldsymbol{s} \boldsymbol{s}}$ \\
\hline PID & 23.33 & 0.447 & 0.326 & 0 \\
\hline Fuzzy Logic & 0.333 & 0.420 & 0.345 & 0 \\
\hline Fuzzy-PID & 2.000 & 0.411 & 0.340 & 0 \\
\hline
\end{tabular}

For the evaluation of the positioning tracking capability, sinusoidal reference signal has been fed to the EHS system as demonstrated in Fig. 9. It is clearly depicted in Fig. 9, the nearest output signal produced by these controllers responded to the required sinusoidal reference signal is Fuzzy-PID, followed by Fuzzy logic and PID controller.

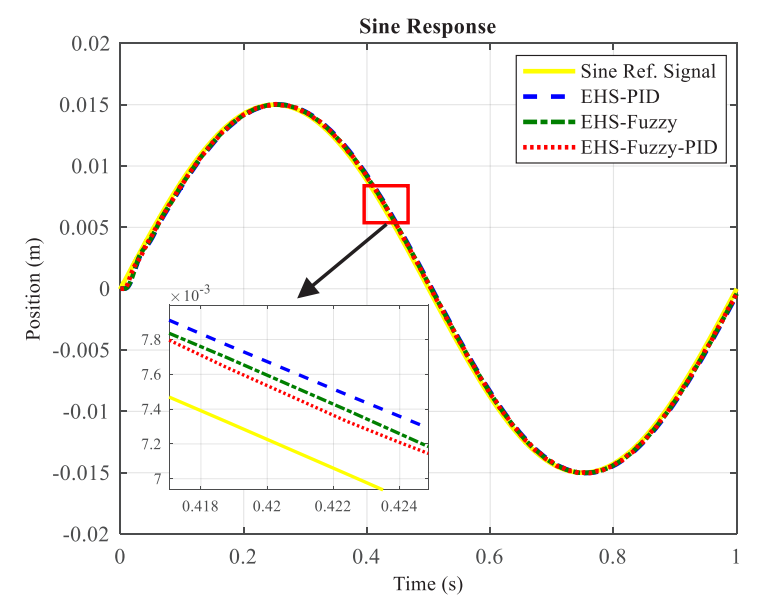

Fig. 9. The response of the controllers to a sinusoidal reference signal

For the more specific analysis, the Root Means Square (RMS) evaluation has been performed as indicated in Table 2.

Table 2. The RMS analysis for the tracking error

\begin{tabular}{|c|c|c|}
\hline Controller & RMS (step) & RMS (sinusoidal) \\
\hline PID & $7.248 \times 10^{-9}$ & $5.224 \times 10^{-4}$ \\
\hline Fuzzy Logic & $2.099 \times 10^{-11}$ & $4.092 \times 10^{-4}$ \\
\hline Fuzzy-PID & $9.950 \times 10^{-13}$ & $3.410 \times 10^{-4}$ \\
\hline
\end{tabular}

The RMS analyses clearly indicate the lower error has been achieved by the Fuzzy-PID controller whether is in step or sinusoidal reference signal. Hence, it can be concluded that by using smallest amount of control effort, the Fuzzy-PID controller is capable to perform better than the conventional Fuzzy and PID controllers.

\section{Conclusion}

In this paper, three different type of controllers, which are PID, Fuzzy logic and Fuzzy-PID controllers have been successfully developed and applied to the nonlinear EHS system. The performances of these controllers have been evaluated and compared to the transient response and the steady-state error analysis. The positioning tracking capability also evaluated via different type of trajectories. As a result, the numerical analyses indicate the hybrid Fuzzy-PID is able to perform better compared to PID and Fuzzy controllers. Approximately $20 \%$ of improvement in the tracking error has been obtained by using the Fuzzy-PID controller.

\section{Acknowledgement}

The support of Centre for Research and Innovation Management (CRIM), Universiti Teknikal Malaysia Melaka (UTeM) and Ministry of Education (MOE) are greatly acknowledged. The research was funded by Short Term Grant No. (PJP/2017/FKE/HI11/S01534) and Fundamental Research Grant Scheme (FRGS) Grant No. FRGS/1/2017/TK04/FKECERIA/F00333.

\section{References}

1. R. Ghazali, C. C. Soon, H. I. Jaafar, Y. M. Sam, and M. F. Rahmat, "System Identification of Electrohydraulic Actuator System with Pressure and Load Effects," in IEEE International Conference on Control System, Computing and Engineering, 2014, pp. 256-260.

2. C. C. Soon, R. Ghazali, H. I. Jaafar, S. Y. S. Hussien, Y. M. Sam, and M. F. Rahmat, "Controller Parameter Optimization for an Electro-hydraulic Actuator System based on Particle Swarm Optimization," J. Teknol., vol. 78, no. 6-13, pp. 101-108, 2016.

3. C. C. Soon, R. Ghazali, H. I. Jaafar, S. Y. S. Hussien, Y. M. Sam, and M. F. Rahmat, "The Effects of Parameter Variation in Open-Loop and Closed-Loop Control Scheme for an Electrohydraulic Actuator System," Int. J. Control Autom., vol. 9, no. 11, pp. 283-294, 2016.

4. M. Heikkilä and M. Linjama, "Displacement control of a mobile crane using a digital hydraulic power management system," Mechatronics, vol. 23, no. 4, pp. 452-461, 2013.

5. R. He, X. Liu, and C. Liu, "Brake Performance Analysis of ABS for Eddy Current and Electrohydraulic Hybrid Brake System," Math. Probl. Eng., vol. 2013, 2013.

6. R. Ghazali, Y. M. Sam, M. F. Rahmat, D. Hanafi, R. 
Ngadengon, and Zulfatman, "Point-to-point trajectory tracking with discrete sliding mode control of an electro-hydraulic actuator system," in Proceedings - IEEE Student Conference on Research and Development, SCOReD, 2011, pp. 148-153.

7. H. Songshan, J. Zongxia, W. Chengwen, and S. Yaoxing, "Fuzzy Robust Nonlinear Control Approach for Electro-Hydraulic Flight Motion Simulator," Chinese J. Aeronaut., vol. 28, no. 1, pp. 294-304, 2015.

8. J. Zhao, G. Shen, W. Zhu, C. Yang, and S. K. Agrawal, "Force Tracking Control of an ElectroHydraulic Control Loading System on a Flight Simulator Using Inverse Model Control and a Damping Compensator," Trans. Inst. Meas. Control, pp. 1-13, 2016.

9. H. C. Pedersen, T. O. Andersen, and B. K. Nielsen, "Comparison of Methods for Modeling a Hydraulic Loader Crane With Flexible Translational Links," J. Dyn. Syst. Meas. Control, vol. 137, no. 10, pp. 115, 2015.

10. S. Chakraborty and R. Meena, "Saving Time by Tip Control \& Automation of Knuckle and Boom Hydraulic Crane," Int. J. Hybrid Inf. Technol., vol. 9, no. 4, pp. 235-254, 2016.

11. Y. Chu, F. Sanfilippo, V. Asoy, and H. Zhang, “An Effective Heave Compensation and Anti-Sway Control Approach for Offshore Hydraulic Crane Operations," in IEEE International Conference on Mechatronics and Automation, (ICMA), 2014, pp. 1282-1287.

12. N. H. Izzuddin, A. 'Athif M. Faudzi, M. R. Johary, and K. Osman, "System Identification and Predictive Functional Control for Electro-hydraulic Actuator System," in IEEE International Symposium on Robotics and Intelligent Sensors (IRIS), 2015, pp. 138-143.

13. J. Yao, G. Jiang, S. Gao, H. Yan, and D. Di, "Particle Swarm Optimization-Based Neural Network Control for an Electro-Hydraulic Servo System," J. Vib. Control, vol. 20, no. 9, pp. 13691377, 2014.

14. C. C. Soon, R. Ghazali, H. I. Zaafar, S. M. Rozali, Y. M. Sam, and M. F. Rahmat, "The Effects of Pressure Variation in Sliding Mode Controller with Optimized PID Sliding Surface," in Asian Simulation Conference, 2017, pp. 104-115.

15. J. Yao, H. Yu, M. Dietz, R. Xiao, S. Chen, T. Wang, and Q. Niu, "Acceleration Harmonic Estimation for a Hydraulic Shaking Table by Using Particle Swarm Optimization," Trans. Inst. Meas. Control, vol. 39, no. 5, pp. 738-747, 2017.

16. C. C. Soon, R. Ghazali, H. I. Jaafar, S. Y. S. Hussien, S. M. Rozali, and M. Z. A. Rashid, "Optimization of Sliding Mode Control using
Particle Swarm Algorithm for an Electro-Hydraulic Actuator System," J. Telecommun. Electron. Comput. Eng., vol. 8, no. 7, pp. 71-76, 2016.

17. S. M. Rozali, N. S. Farhana, M. N. Kamarudin, A. F. Z. Abidin, M. F. Rahmat, A. R. Husain, and C. C. Soon, "Robust Control Design of Nonlinear System via Backstepping-PSO with Sliding Mode Techniques," in Asian Simulation Conference, 2017, pp. 27-37.

18. C. C. Soon, R. Ghazali, H. I. Jaafar, and S. Y. S. Hussien, "Sliding Mode Controller Design with Optimized PID Sliding Surface Using Particle Swarm Algorithm," Procedia Comput. Sci., vol. 105, pp. 235-239, 2017.

19. Z. Chen, X. Yuan, B. Ji, P. Wang, and H. Tian, "Design of a Fractional Order PID Controller for Hydraulic Turbine Regulating System Using Chaotic Non-Dominated Sorting Genetic Algorithm II," Energy Convers. Manag., vol. 84, pp. 390-404, 2014.

20. A. Montazeri, C. West, S. D. Monk, and C. J. Taylor, "Dynamic Modelling and Parameter Estimation of a Hydraulic Robot Manipulator Using a Multi-objective Genetic Algorithm," Int. J. Control, vol. 90, no. 4, pp. 661-683, 2016.

21. T. Samakwong and W. Assawinchaichote, "PID Controller Design for Electro-hydraulic Servo Valve System with Genetic Algorithm," Procedia Comput. Sci., vol. 86, pp. 91-94, 2016.

22. M. Dangor, O. A. Dahunsi, J. O. Pedro, and M. M. Ali, "Evolutionary Algorithm-Based PID Controller Tuning for Nonlinear Quarter-Car Electrohydraulic Vehicle Suspensions," Nonlinear Dyn., vol. 78, no. 4, pp. 2795-2810, 2014.

23. Y. C. Hung, F. J. Lin, J. C. Hwang, J. K. Chang, and K. C. Ruan, "Wavelet Fuzzy Neural Network with Asymmetric Membership Function Controller for Electric Power Steering System via Improved Differential Evolution," IEEE Trans. Power Electron., vol. 30, no. 4, pp. 2350-2362, 2015.

24. C. C. Soon, R. Ghazali, H. I. Jaafar, and S. Y. S. Hussien, "PID Controller Tuning Optimization using Gradient Descent Technique for an Electrohydraulic Servo System," J. Teknol. Sci. Eng., vol. 77, no. 21, pp. 33-39, 2015.

25. C. C. Soon, R. Ghazali, H. I. Jaafar, S. Y. S. Hussien, S. M. Rozali, and M. Z. A. Rashid, "Position Tracking Optimization for an Electrohydraulic Actuator System," J. Telecommun. Electron. Comput. Eng., vol. 8, no. 7, pp. 1-6, 2016.

26. P. Pratumsuwan and A. Junchangpood, "Force and Position Control in the Electro-Hydraulic System by using a MIMO Fuzzy Controller," in IEEE Conference on Industrial Electronics and Applications, (ICIEA), 2013, pp. 1462-1467. 